\title{
Computational Fluid Dynamics (CFD) Analysis of Phthalic Anhydride's Yield Using Lab Synthesized and Commercially Available $\left(\mathrm{V}_{2} \mathrm{O}_{5} / \mathrm{TiO}_{2}\right)$ Catalyst
}

\author{
Ali Sarosh \\ School of Chemical and Materials Engineering \\ National University of Sciences and Technology \\ Islamabad, Pakistan \\ ali-che-ms01@scme.nust.edu.pk
}

Erum Pervaiz

School of Chemical and Materials Engineering

National University of Sciences and Technology

Islamabad, Pakistan

erum.pervaiz@scme.nust.edu.pk

\author{
Arshad Hussain \\ School of Chemical and Materials Engineering \\ National University of Sciences and Technology \\ Islamabad, Pakistan \\ arshad.hussain@scme.nust.edu.pk \\ Muhammad Ahsan \\ School of Chemical and Materials Engineering \\ National University of Sciences and Technology \\ Islamabad, Pakistan \\ ahsan@scme.nust.edu.pk
}

\begin{abstract}
V}_{2} \mathrm{O}_{5} / \mathrm{TiO}_{2}$ is an important catalyst used in many industrial reactions like selective oxidation of 0 -xylene to phthalic anhydride, selective catalytic reduction of $\mathrm{NO}_{\mathrm{x}}$, selective oxidation of alkanes, etc. The partial oxidation of o-xylene to synthesize phthalic anhydride is an exothermic reaction and leaves hot spots on the catalyst's surface. The yield of phthalic anhydride strongly depends on the activity and stability of the catalyst. In this work, a computational fluid dynamics (CFD) analysis has been conducted to compare the yield of lab prepared catalyst with the commercially used catalyst. This work is first attempt to simulate $\mathrm{V}_{2} \mathrm{O}_{5} / \mathrm{TiO}_{2}$ catalyst for cracking heavy hydrocarbons in the petrochemical industry using $\mathrm{k}-\varepsilon$ turbulence and species transport models in CFD. The results obtained are in the form of scaled residuals, area-weighted average, and contours of pressure and temperature. Simulation results of lab synthesized and commercially used catalysts, applying finite volume method (FVM) are compared, which emphasize the scope of CFD modeling in the catalytic cracking process of petrochemical industry.
\end{abstract}

Keywords- $\mathrm{V}_{2} \mathrm{O}_{5} / \mathrm{TiO}_{2}$; computational fluid dynamics; CFD; hydrocarbon cracking; hydrodynamics; $k$-E turbulence model; oxylene; phthalic anhydride

\section{INTRODUCTION}

Catalytic cracking is one of the fundamental processes in petrochemical industries. Heavy hydrocarbons are cracked catalytically to give valuable products. For example, the partial oxidation of o-xylene with air is carried out in fixed bed reactor to produce phthalic anhydride. The reaction takes place in the gas phase in which the reactor is filled with catalyst $\mathrm{V}_{2} \mathrm{O}_{5} / \mathrm{TiO}_{2}$. It is a selective oxidation process in which the ratio of o-xylene to air is set below the explosive limit [1]. As o-xylene reacts with air, the reaction becomes highly exothermic leaving hot spots on catalyst pellets which deactivate the catalyst. The industrial reactor is designed on low ratio of the tube to particle diameter to remove the heat of reaction instantly and to avoid catalyst hot spots and deactivation [1]. Due to inefficient oxidation and rise in reaction temperature from $\left(245^{\circ} \mathrm{C}\right.$ to $480^{\circ} \mathrm{C}$ ) the yield of phthalic anhydride decreases. Consequently, series of byproducts like methyl maleic anhydride, benzoic acid, maleic anhydride, o-toluic acid, carbon dioxide, carbon monoxide and water are produced. Phthalic anhydride is the intermediate product for the manufacturing of many chemicals. It acts as a plasticizer for the production of flexible polyvinyl chloride, polyester resins and is used as modifier for rubbers and polymers [1-7].

An attempt was made to develop $\mathrm{V}_{2} \mathrm{O}_{5} / \mathrm{TiO}_{2}$ catalyst on lab scale with improved chemical and physical properties. Through the sol-gel method, the nanosize catalyst was synthesized using vanadyl acetylacetonate and titanium isopropoxide. A controlled number of sulfates was introduced into the sample which provides acidic nature of the solid catalyst. The addition of sulfates enhanced the redox properties of the catalyst. The crystalline structure and morphological analysis of lab prepared catalyst have been done by using X-Ray diffraction (XRD) and scanning electron microscopy (SEM). Computational fluid dynamics (CFD) analysis has been conducted to compare the activity of the commercially used catalyst and lab prepared catalyst. A three-dimensional reactor grid having triangular meshing and ceramics monolith substrate for catalyst support has been constructed in Ansys Fluent. The ceramics monolith substrate was made to control the heat transfer. The monolithic structures work more efficiently than random packing of catalyst [8]. In this research work, three-dimensional hydrodynamics and reaction study have been done using Ansys Fluent to compare the yield of phthalic anhydride and 
convergence of reactants. Through reactor grids, comprehensive study of species transport, reaction mechanism, and hydrodynamics in term of scaled residuals, static pressure, static temperature, and area weighted average, has been conducted. The simulation results showed complete conversion of o-xylene to phthalic anhydride, without any byproduct formation. The temperature profile and hydrodynamics in the reactor are evaluated by applying industrial conditions. To our knowledge, this is the first attempt to model heavy hydrocarbon cracking in the presence of $\mathrm{V}_{2} \mathrm{O}_{5} / \mathrm{TiO}_{2}$ using CFD with Finite Volume Method (FVM) by implemented suitable governing equations and boundary conditions.

\section{CFD MODELING}

CFD helps to design, model, and analyze industrial applications. Simulation of ceramics monolith substrate reactor has been conducted to study the partial oxidation of o-xylene with air to produce phthalic anhydride. This research may be considered as a meager contribution to better understanding of the interaction between gas phase reactants in the presence of a catalyst. The objectives of this CFD modeling are 1) to compare the yield of phthalic anhydride obtained from commercially used catalyst and lab prepared catalyst, 2) to understand reaction chemistry and heat transport in the reactor, 3 ) to optimize operating conditions of the reactor to maximize the yield of phthalic anhydride [9].

\section{A. Turbulance Model}

The model equations for $\mathrm{k}$ and $\varepsilon$ in realizable $\mathrm{k}-\varepsilon$ model have already been presented in [10-12]

$\frac{\partial}{\partial t}(\rho k)+\frac{\partial}{\partial x_{j}}\left(\rho k u_{j}\right)=\frac{\partial}{\partial x_{j}}\left[\left(\mu+\frac{\mu_{t}}{\sigma_{k}}\right) \frac{\partial k}{\partial x_{j}}\right]+G_{k}+G_{b}-\rho \varepsilon-Y_{M}+S_{k}$

and

$\frac{\partial}{\partial t}(\rho \varepsilon)+\frac{\partial}{\partial x_{j}}\left(\rho \varepsilon u_{j}\right)=\frac{\partial}{\partial x_{j}}\left[\left(\mu+\frac{\mu_{q}}{\sigma_{\varepsilon}}\right) \frac{\partial \varepsilon}{\partial x_{j}}\right]+\rho C_{1} S_{\varepsilon}-\rho C_{2} \frac{\varepsilon^{2}}{k+\sqrt{v \varepsilon}}+C_{1 \varepsilon} \frac{\varepsilon}{k} C_{3 \varepsilon} G_{b}+S_{\varepsilon}(2)$

Where

$C_{1}=\max \left[0.43, \frac{\eta}{\eta+5}\right], \eta=S \frac{k}{\varepsilon}, S=\sqrt{2 S_{i j} S_{i j}}$ from

As in other $\mathrm{k}-\varepsilon$ models, the eddy viscosity is computed

$$
\mu_{t}=\rho C_{\mu} \frac{k^{2}}{\varepsilon}
$$

The difference between the realizable $\mathrm{k}-\varepsilon$ model and the standard RNG $\mathrm{k}-\varepsilon$ models is that $\mathrm{C}_{\mu}$ is no longer a constant. It is computed from

$$
C_{\mu}=\frac{1}{A_{o}+A_{s} \frac{k U^{*}}{\varepsilon}}
$$

where

$$
U^{*} \equiv \sqrt{S_{i j} S_{i j}+\Omega_{i j} \Omega_{i j}}
$$

and

$\tilde{\Omega}_{i j}=\Omega_{i j}-2 \varepsilon_{i j k} \omega_{k}$

$\Omega_{i j}=\bar{\Omega}_{i j}-\varepsilon_{i j k} \omega_{k}$

Here, $\bar{\Omega}_{\mathrm{ij}}$ is the mean rate-of-rotation tensor viewed in a rotating reference frame with the angular velocity $\omega_{\mathrm{k}}$. The model constants $A_{o}$ and $A_{s}$ are given by

$$
A_{o}=4.04, \quad A_{s}=\sqrt{6} \cos \varphi
$$

where

$\varphi=\frac{1}{3} \cos ^{-1}(\sqrt{6} W), W=\frac{S_{i j} S_{j k} S_{k i}}{\tilde{S}^{3}}, \tilde{S}=\sqrt{S_{i j} S_{i j}}, S_{i j}=\frac{1}{2}\left(\frac{\partial u_{j}}{\partial x_{i}}+\frac{\partial u_{i}}{\partial x_{j}}\right)$

\section{B. Species Transport Model}

A particle undergoing an exothermic reaction in the gas phase is shown schematically in Figure 1 where $T_{p}$ and $T_{\infty}$ are the temperatures while $\mathrm{C}_{\mathrm{d}, \mathrm{b}}, \mathrm{C}_{\mathrm{d}, \mathrm{s}}$, and $\mathrm{C}_{\mathrm{k}}$ are the concentrations [12-18]. Ansys Fluent uses the following equation to describe the rate of reaction $r$ of a particle surface species $j$ and the gas phase species $\eta$. The reaction stoichiometry of reaction $r$, in this case, is described by

Particle species $j(\mathrm{~s})+$ gas phase species $\eta \rightarrow$ products $N_{r}$

$\bar{R}_{j, r}=A_{p} \eta_{r} Y_{j} R_{j, r}$

The effectiveness factor $\eta_{r}$ is related to the surface area and can be used in each reaction in the case of multiple reactions. $D_{o, r}$ is given by

$$
D_{o, r}=C_{1, r} \frac{\left[T_{p}+T_{\infty} / 2\right]^{0.75}}{d_{p}}
$$

The kinetic rate of reaction $r$ is defined as

$$
R_{k i n, r}=A_{r} T^{\beta_{r}} e^{-\left(E_{r} / R T\right)}
$$

The rate of depletion of particle surface species for the reaction order $\mathrm{N}_{\mathrm{r}}=1$ is given as,

$$
\bar{R}_{j, r}=A_{p} \eta_{r} Y_{j} p_{n} \frac{R_{k i n, r} D_{o, t}}{D_{o, r}+R_{k i n, r}}
$$

For reaction order $\mathrm{N}_{\mathrm{r}}=0$, equation (15) gives (11)

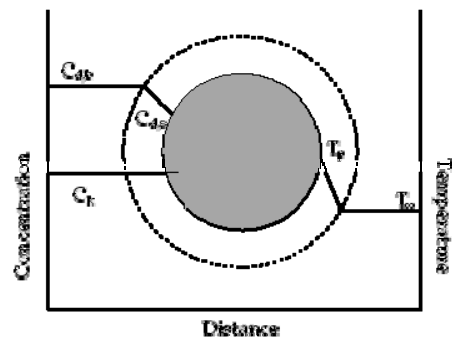

Fig. 1. A reacting particle in the multiple surface reactions model [12]

The model equations required two important characteristics of the catalyst: 1) inertial resistance 2) viscous resistance. The inertial resistance of a catalyst is the built-in inertia which 
enables the catalyst to enhance the rate of reactants convergence into products but never gets consumed in a chemical reaction. It is observed that if a nanoscale catalyst is used in the reaction, the convergence of o-xylene to phthalic anhydride is increased.

\section{Boundary Conditions}

Gambit $^{\mathrm{TM}}$ pre-processor is used to construct the $3 \mathrm{D}$ geometry of the system. The geometry of ceramic monolith substrate has been discretized using 125772 cells, 271496 faces, and 33608 nodes. Grid size analysis has been carried out using three different mesh intervals. The simulation results from different geometries did not show any significant difference. Triangular grids are used in the geometry of fixed bed reactor as shown in Figures 2 and 3. The geometry dimensions are $\mathrm{x}=0.31 \mathrm{~m}, \mathrm{y}=0.128 \mathrm{~m}, \mathrm{z}=0.028 \mathrm{~m}$. O-xylene and air entered with a uniform velocity of $50 \mathrm{~m} / \mathrm{s}$, pass through a ceramic monolith substrate of square-shaped channels and then exit through the outlet. The substrate is impermeable in $\mathrm{Y}$ and $\mathrm{Z}$ directions, which has been modeled by specifying loss coefficients three orders higher than in $\mathrm{X}$ direction. The properties of species, gases, and catalyst bed are mentioned in Tables I and II.

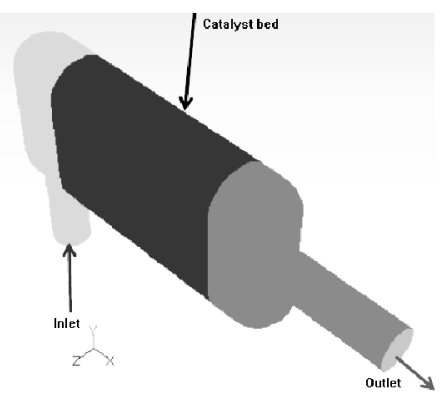

Fig. 2. Schematic diagram of fixed bed reactor

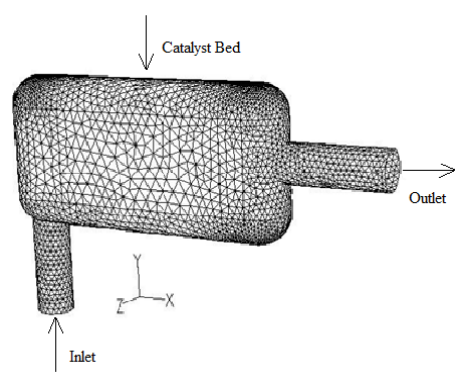

Fig. 3. Grids of fixed bed reactor

TABLE I. PROPERTIES OF SPECIES [19]

\begin{tabular}{|c|c|}
\hline Reaction Type & Surface of catalyst \\
\hline Number of Reactants & 2 \\
\hline Species & $\mathrm{C}_{8} \mathrm{H}_{10}, \mathrm{O}_{2}$ \\
\hline Stoichiometric Coefficient & 1,3 \\
\hline Rate Exponent & $1,0.5$ \\
\hline Arrhenius Rate & $27000 \mathrm{~J} / \mathrm{Kg}$ mole \\
\hline Pre-Exponential Factor & $4.12 \times 10^{11}$ \\
\hline Number of products & 2 \\
\hline Species & $\mathrm{C}_{8} \mathrm{H}_{4} \mathrm{O}_{3}, \mathrm{H}_{2} \mathrm{O}$ \\
\hline Stoichiometric Co-efficient & 1,3 \\
\hline Rate Exponent & 0,0 \\
\hline
\end{tabular}

TABLE II. PROPERTIES OF REACTANTS, PRODUCTS AND CATALYSTS [22]

\begin{tabular}{|c|c|c|c|c|}
\hline $\begin{array}{l}\text { Properties } \\
\text { (Units) }\end{array}$ & $\frac{\stackrel{0}{\tilde{e}}}{\grave{d}}$ & 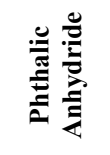 & 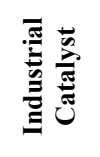 & 苞 \\
\hline Density $\left(\mathrm{Kg} / \mathrm{m}^{3}\right)$ & 880 & 1530 & 5067 & 5067 \\
\hline Temp. (K) & 298.15 & 367 & 630 & 780 \\
\hline $\mathrm{Cp}(\mathrm{J} / \mathrm{Kg} . \mathrm{K})$ & 132.5 & 160 & 721.89 & 721.89 \\
\hline $\begin{array}{c}\text { Thermal } \\
\text { Conductivity } \\
(\mathrm{W} / \mathrm{m} . \mathrm{K})\end{array}$ & 0.131 & $\begin{array}{l}\text { Kinetic } \\
\text { Theory }\end{array}$ & 46.3 & 46.3 \\
\hline Viscosity (Kg/m.s) & 0.760 & 0.00064 & $\begin{array}{l}\text { Kinetic } \\
\text { Theory }\end{array}$ & $\begin{array}{l}\text { Kinetic } \\
\text { Theory }\end{array}$ \\
\hline $\begin{array}{c}\text { Molecular } \\
\text { Weight } \\
(\mathrm{Kg} / \mathrm{Kmole})\end{array}$ & 106.16 & 148 & 281.9 & 261.6 \\
\hline $\begin{array}{c}\text { Standard State } \\
\text { Enthalpy } \\
(\mathrm{J} / \mathrm{mole})\end{array}$ & 19000 & -3259.4 & -880 & -880 \\
\hline
\end{tabular}

\section{Assumptions}

1) The ideal gas law is assumed to hold while calculating the pressure-velocity variations on account of convergence and molar expansion due to heavy hydrocarbon cracking and gas phase temperature [20]. 2) Catalyst particles are fixed as a cluster of a bed to account for the observed velocity of the gas [20]. 3) Mass and heat resistance are assumed as negligible Assuming plug flow conditions for both phases hence back mixing of multi-phases is neglected [20-21].

\section{E. Simulation Setup}

Ansys Fluent worked for 100 iterations on an Intel Core i5 CPU with the 32-bit operating system and 4GB RAM. The simulation steps are shown in Figure 4. Ansys Fluent shows remarkable convergence while solving problems. There is no rule to predict convergence because scaled residue for one type of model doesn't mean it's same for another. Therefore, it is important to examine and monitor the results through Drag's law and heat transfer coefficient. For all equations, the criteria of scaled residue must decrease to $10^{-3}$ except for radiations, energy and combustion reactions which are $10^{-6}$. For this work, scaled residuals decrease for both lab catalyst and commercial catalyst up to $10^{-6}$ [12].

\section{RESULTS AND DISCUSSION}

Simulations of lab prepared catalyst and commercial catalyst in the fixed bed reactor were run for 2 hours. Constant catalytic performance was observed because of strong adhesion of lab $\mathrm{V}_{2} \mathrm{O}_{5} / \mathrm{TiO}_{2}$ particles on monolith ceramics substrate. Lab synthesized $\mathrm{V}_{2} \mathrm{O}_{5} / \mathrm{TiO}_{2}$ (anatase) indicated the stability in catalytic behavior after the reaction. The lab catalyst showed significantly higher conversion of o-xylene to phthalic anhydride due to better catalyst activity as shown in Figure 5. The comparison of the convergence of o-xylene for lab catalyst and commercially used catalyst is shown in Figures 5-6. The lower selectivity of phthalic anhydride in the case of commercial catalyst is due to lower surface area of the catalyst which leads to the formation of intermediates and byproducts 
like $\mathrm{CO}_{\mathrm{x}}$. The percentage yield of commercial catalyst and labprepared catalyst has been calculated as $66.7 \%$ and $80 \%$ respectively. Table III shows the yield comparison among other models and the results obtained in this work. It is seen that maximum yield of phthalic anhydride can be achieved through lab synthesized catalyst.

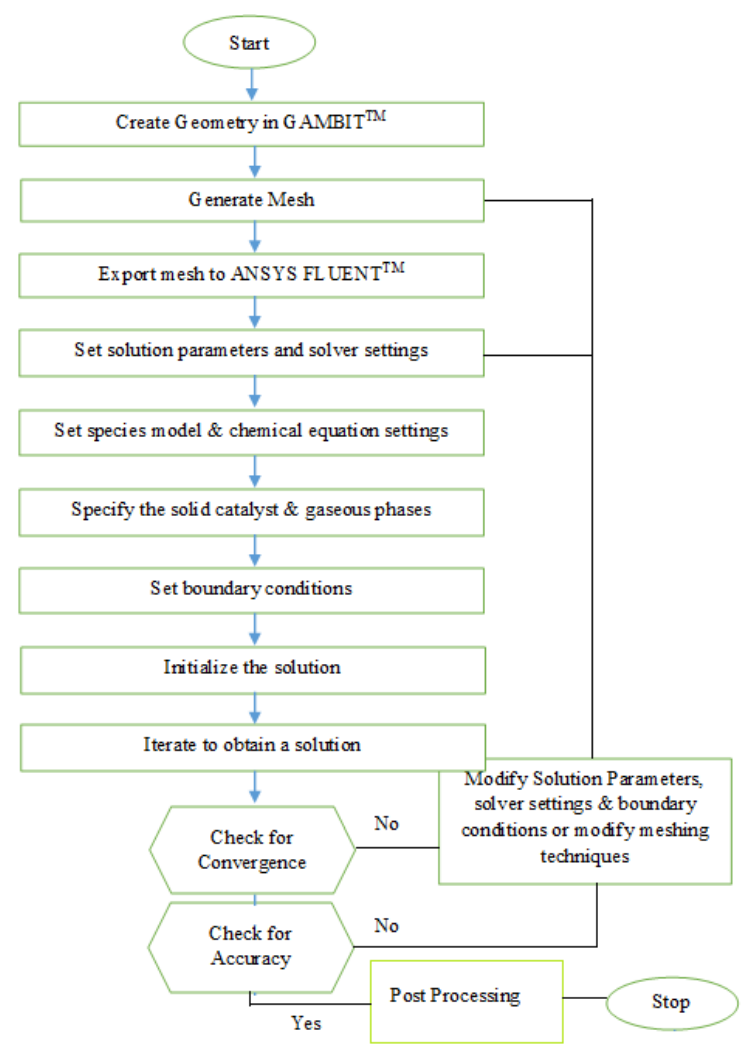

Fig. 4. Block diagram of simulation steps

TABLE III. THE YIELDS OF PHTHALIC ANHYDRIDE (PA) COMPARISON CALCULATED FROM THIS MODEL WITH OTHER MODELS AND INDUSTRY DATA $[1,13]$.

\begin{tabular}{|c|c|c|c|}
\hline Comparison 1 & $\begin{array}{c}\text { Yield of PA } \\
\text { (This work) }\end{array}$ & $\begin{array}{c}\text { Yield of PA } \\
\text { [13] }\end{array}$ & Error \\
\hline $\begin{array}{c}\text { Commercial } \\
\text { Catalyst }\end{array}$ & $66.7 \%$ & & $0.44 \%$ \\
\cline { 1 - 1 } $\begin{array}{c}\text { Lab prepared } \\
\text { Catalyst }\end{array}$ & $80 \%$ & $67 \%$ & $19.40 \%$ \\
\hline Comparison 2 & & Yield of PA [1] & \\
\hline $\begin{array}{c}\text { Commercial } \\
\text { Catalyst }\end{array}$ & $66.7 \%$ & $\begin{array}{c}79.5 \% \\
\text { (With Industrial } \\
\text { Values) }\end{array}$ & $16.10 \%$ \\
\cline { 1 - 2 } $\begin{array}{c}\text { Lab prepared } \\
\text { Catalyst }\end{array}$ & $80 \%$ & $0.62 \%$ \\
\hline Comparison 3 & $66.7 \%$ & $\begin{array}{c}\text { Yield of PA [1] } \\
\text { (Under }\end{array}$ & $17.24 \%$ \\
\hline $\begin{array}{c}\text { Commercial } \\
\text { Catalyst }\end{array}$ & $80 \%$ & $\begin{array}{c}\text { optimum } \\
\text { conditions) }\end{array}$ & $0.74 \%$ \\
\hline $\begin{array}{c}\text { Lab prepared } \\
\text { Catalyst }\end{array}$ & &
\end{tabular}

This work also predicts the temperature and conversion profiles in case of lab prepared and commercially used catalysts. For combustion reactions, energy and heavy hydrocarbon cracking scaled residuals must reach to $10^{-6}$. Figures 5 and 6 show the rate of conversion from o-xylene to phthalic anhydride, in which equation of continuity, species transport model, and turbulence model was applied. Threedimensional velocity profile of catalysts, energy and thermal conductivity were calculated. Both commercial and labprepared catalysts showed $10^{-6}$ convergence in $2 \mathrm{hrs}$ with 90 and 100 iterations respectively. The lab prepared catalyst showed a sudden drop when it reached 80 iterations in residuals which may be because of composition change [10]. The temperature and concentration were recorded at every point of the reactor. It helped in determining the optimum operating conditions to avoid deactivation of catalyst and side reactions. The temperature profile was obtained with time by solving the model equations.

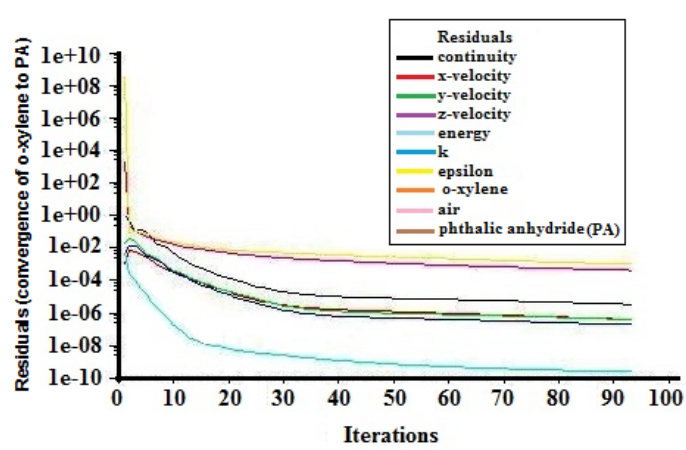

Fig. 5. Scaled residuals of commercial catalyst

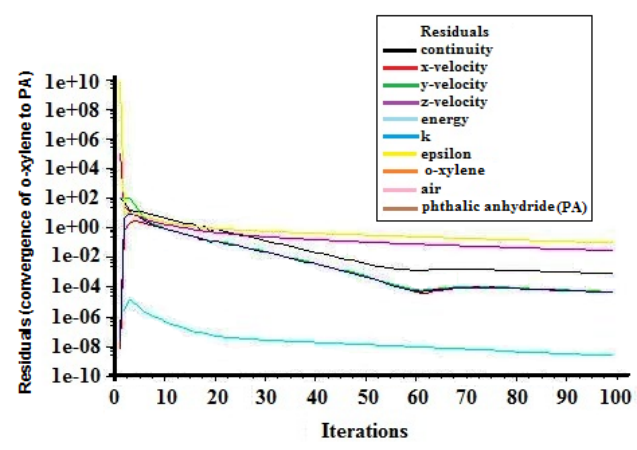

Fig. 6. Scaled residuals of lab prepared catalyst

In Figures 7-8, the contours show the temperature regimes of both commercially used and lab-prepared catalysts in radial and axial directions. Due to the highly exothermic reaction, heat dispersion has been observed in the radial direction, which may be attributed to radiation from solid to solid, from gas to solids or to a combination of both mechanisms. Unlike the commercially used catalyst, the lab prepared nanoscale $\mathrm{V}_{2} \mathrm{O}_{5} / \mathrm{TiO}_{2}$ showed remarkably better temperature profiles. The temperature profile of lab prepared catalyst showed constant increment while the change in commercial catalyst varies. The results of lab synthesized nanocatalyst showed the best reaction temperature profile in order to get maximum yield of phthalic anhydride. Due to low activity of the commercial catalyst, the reaction temperature reached the upper limit, as a result of which hot spots were formed on the catalyst surface which caused the deactivation of the commercial catalyst. Furthermore, high catalytic temperature makes the small 
crystallites of active phase to agglomerate, generally termed as thermal sintering. The difference in the results of both catalysts may be linked to variations in size, catalyst shape and the bed porosity of. The porosity of bed effects the rate of turbulence which leads to variations in heat transport [2, 18, 23].

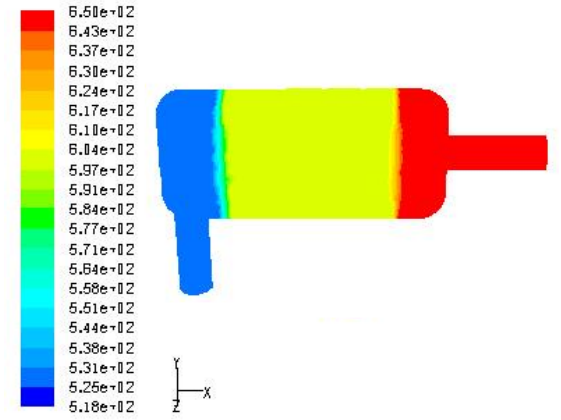

Fig. 7. Temperature contours of commercial catalyst (K)

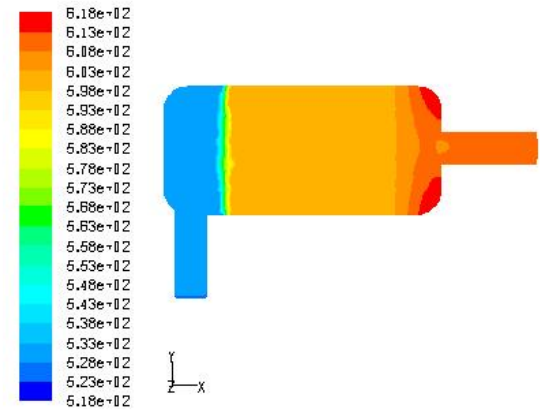

Fig. 8. Temperature contours of lab prepared catalyst (K)

The CFD modeling done in this work provided point to point temperature and conversion by specifying the following conditions: a) inlet and outlet temperatures b) inlet composition of feed gas c) reactor surface temperature d) gas mass flow rate e) reactor size $f$ ) type of reaction $g$ ) size of catalyst $[10,11]$. The study of this type of reactor and reaction system is highly sensitive to even a small variation in temperature, which can directly affect the concentrations of the reactants and inlet gas temperature. Pressure-velocity coupling model was used to find the inlet pressure of gases for fixed bed reactor. Two-phase flow regions require averaging of the fluid properties. These properties can lead to large errors due to the difference in magnitude order. An area-weighted average can lead to a significant improvement in the result quality and indicates suitable reaction mechanism and conditions. In the case of a micron-sized (commercially used) catalyst, high static pressure and high temperature are required to produce phthalic anhydride. An area-weighted average of the static pressure of commercially used and lab-prepared catalysts is shown in Figures 9 and10 respectively. The results of commercial catalyst showed that it requires high pressure to achieve reaction condition. At $260 \mathrm{KPa}$ the reaction starts which requires high energy. The lab prepared catalyst having nano particle size (strong adhesion with ceramics monolith substrate) showed remarkably controlled pressure conditions. The difference in particle size has a noticeable influence on the convergence values in Figures 9-10.

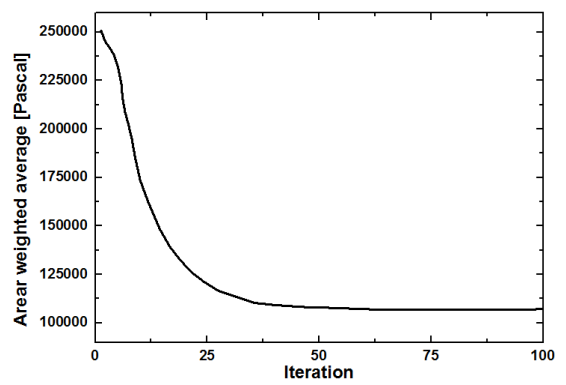

Fig. 9. Convergence history of pressure of commercial catalyst

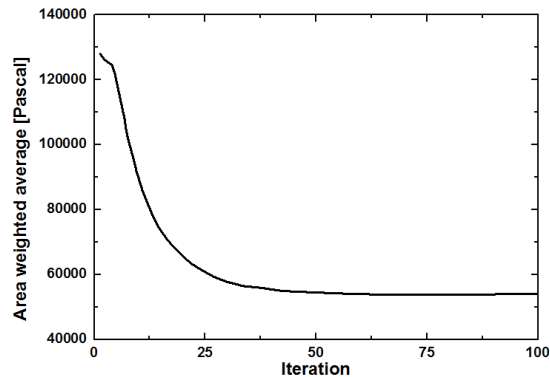

Fig. 10. Convergence history of pressure of lab prepared catalyst

\section{CONCLUSION}

A CFD analysis has been done for nanoscale and commercially available $\mathrm{V}_{2} \mathrm{O}_{5} / \mathrm{TiO}_{2}$ catalyst for the partial oxidation of o-xylene to phthalic anhydride. A threedimensional multiphase flow reaction model for fixed bed reactor was developed by using finite-volume method solver, Ansys Fluent. Scaled residuals, temperature profile, contours of pressure and area weighted average are predicted by applying species transport and k- $\varepsilon$ turbulence models. In this work, CFD simulations have been performed to predict the conversion of o-xylene to phthalic anhydride using $\mathrm{V}_{2} \mathrm{O}_{5} / \mathrm{TiO}_{2}$ as a catalyst. The results of lab prepared catalyst showed better catalyst activity compared to the commercially used catalyst. FVM efficiently solved many model equations both for solid and gas phases. The nanoscale lab prepared catalyst showed better temperature profiles which favors the increase in catalyst's life and phthalic anhydride's yield. The proposed model is applicable for different simulation studies of fixed bed reactor.

\section{REFERENCES}

[1] A.I. Anastasov, "Deactivation of an industrial V2O5-TiO2 catalyst for oxidation of o-xylene into phthalic anhydride", Chemical Engineering and Processing: Process Intensification, Vol. 42, No. 6, pp. 449-460, 2003

[2] H. Zhao, S. Bennici, J. Shen, A. Auroux, "The influence of the preparation method on the structural, acidic and redox properties of V2O5-TiO2/SO4 2- catalysts", Applied Catalysis A: General, Vol. 356, No. 2, pp. 121-128, 2009

[3] M. P. Gimeno, J. Gascon, C. Tellez, J. Herguido, M. Menendez, "Selective oxidation of o-xylene to phthalic anhydride over V2O5/TiO2: kinetic study in a fluidized bed reactor", Chemical Engineering and 
Processing: Process Intensification, Vol. 47, No. 9-10, pp. 1844-1852, 2008

[4] W. Friedrichsen, O. Goehre, Process for the production of phthalic anhydride, U.S. Patent No. 3,509,179, 1970

[5] D.J. Hucknall, Selective oxidation of hydrocarbons, Academic Press, 1974

[6] J.-J. Shyue, M.R. De Guire, "Single-step preparation of mesoporous, anatase-based titanium-vanadium oxide and its application", Journal of the American Chemical Society, Vol. 127, No. 36, pp. 12736-12742, 2005

[7] G. Bond, "Preparation and properties of vanadia/titania monolayer catalysts", Applied Catalysis A: General, Vol. 157, No. 1, pp. 91-103, 1997

[8] G. Groppi, E. Tronconi, C. Cortelli, R. Leanza, "Conductive monolithic catalysts: development and industrial pilot tests for the oxidation of oxylene to phthalic anhydride", Industrial \& Engineering Chemistry Research, Vol. 51, No. 22, pp. 7590-7596, 2011

[9] V.M. Janardhanan, O. Deutschmann, "Computational fluid dynamics of catalytic reactors", in: Modeling and simulation of heterogeneous catalytic reactions: from the molecular process to the technical system, Wiley-VCH, 2011

[10] L. Jiang, X. Fang - Zhi, L. Zheng - Hong, "A CFD modeling of the gassolid two-phase flow in an FCC riser under the electrostatic conditions", Asia-Pacific Journal of Chemical Engineering, Vol. 9, No. 5, pp. 645655,2014

[11] J. Chang, W. Cai, K. Zhang, F. Meng, L. Wang, Y. Yang, "Computational investigation of the hydrodynamics, heat transfer and kinetic reaction in an FCC gasoline riser", Chemical Engineering Science, Vol. 111, pp. 170-179, 2014

[12] I. Fluent, "Fluent 6.3 Users Guide", Fluent documentation, 2006

[13] P. Mulheims, B. Kraushaar-Czarnetzki, "Temperature profiles and process performances of sponge packings as compared to spherical catalysts in the oxidation of o-xylene to phthalic anhydride", Industrial \& Engineering Chemistry Research, Vol. 50, No. 17, pp. 9925-9935, 2011

[14] M. Hoj, T. Kessler, P. Beato, A. D. Jensen, J. D. Grunwaldt, "Structure, activity and kinetics of supported molybdenum oxide and mixed molybdenum-vanadium oxide catalysts prepared by flame spray pyrolysis for propane OHD”, Applied Catalysis A: General, Vol. 472, pp. 29-38, 2014

[15] B. P. Muljadi, M. J. Blunt, A. Q. Raeini, B. Bijeljic, "The Impact of Porous Media Heterogeneity on Non-Darcy Flow Behaviour from PoreScale Simulation", Advances in Water Resources, Vol. 95, pp. 329-340, 2015

[16] A. W. Lothongkum, P. Sethapokin, P. Ouraipryvan, "Simulation of V2O5/TiO2 catalyst activity by central composite design for optimal operating conditions and catalyst life in phthalic anhydride production", Journal of Industrial and Engineering Chemistry, Vol. 25, pp. 288-294, 2014

[17] Y. M. Ferng, K.-Y. Lin, "Investigating effects of BCC and FCC arrangements on flow and heat transfer characteristics in pebbles through CFD methodology", Nuclear Engineering and Design, Vol. 258, pp. 66-75, 2013

[18] D. E. Cormack, G. I. Beattie, "Viscous flow effects in the periodic pressure cycling of gas-phase catalytic reactions", Chemical Engineering Science, Vol. 34, No. 7, pp. 1001-1005, 1979

[19] P. Frank, Phthalic anhydride production, U.S. Patent No. 2,117,359, 1938

[20] P. K. Dasila, I. Choudhury, D. Saraf, S. Chorpa, A. Dalai, "Parametric sensitivity studies in a commercial FCC unit", Advances in Chemical Engineering and Science, Vol. 2, No. 01, pp. 136-149, 2011

[21] H. Ali, S. Rohani, J. P. Corriou, "Modelling and control of a riser type fluid catalytic cracking (FCC) unit", Chemical Engineering Research and Design, Vol. 75, No. 4, pp. 401-412, 1997

[22] P. J. Linstrom, W. Mallard, NIST Chemistry webbook SRD. 69, Available at: https://webbook.nist.gov/chemistry/, 2001
[23] J. Geertsma, "Estimating the coefficient of inertial resistance in fluid flow through porous media", Society of Petroleum Engineers Journal, Vol. 14, No. 05, pp. 445-450, 1974 